\title{
Le
}

SECCIÓN: Educación y espacio
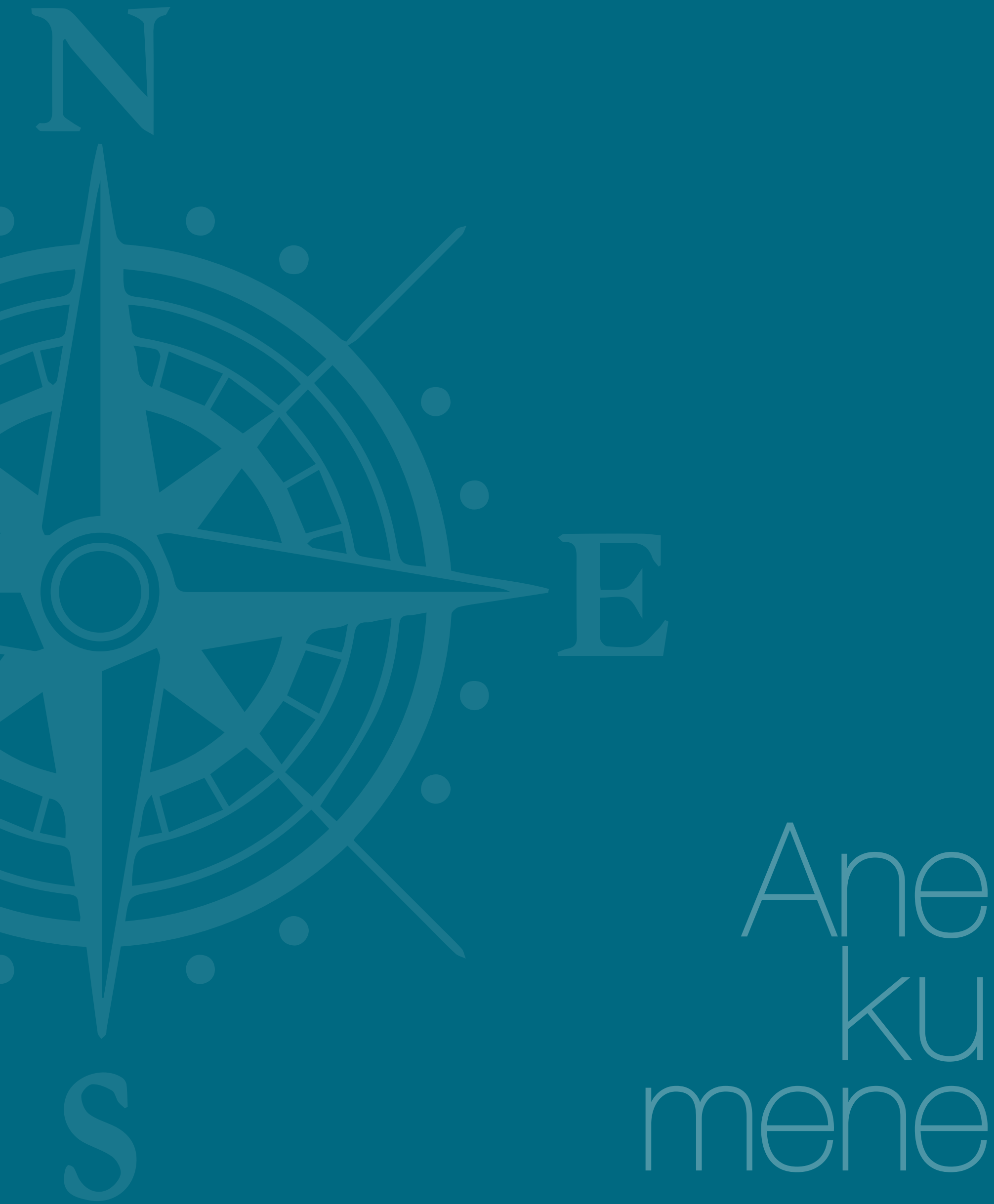


\section{O espaço geográfico e social em relação à literatura}

\section{El espacio geográfico y social en relación con la literatura The Geographical and Social Space in Relation to Literature}

Maristela Maria de Moraes*

José Carlos da Silva Telles**

\begin{abstract}
Resumo
A questão referente à interdisciplinaridade é um tema recorrente na educação do Brasil. Esse termo está presente nos documentos oficiais que regulam o ensino, os Parâmetros Curriculares Nacionais - PCNs e as Orientações Curriculares para o Ensino Médio - OCEM. Levando em conta a importância dada à integração das diferentes áreas do conhecimento na escola, busca-se neste texto verificar as possibilidades de estudo do conceito de espaço, sob uma perspectiva de interface para as áreas da geografia, sociologia e literatura. A literatura, embora não tenha compromisso com um retrato fiel da realidade, a representa através da verossimilhança, incluindo nisto o meio (físico e social) em que a personagem adquire suas motivações e vive a trama. Assim, a escolha de uma obra literária, levando em conta o tema que se pretende trabalhar na área da sociologia ou geografia, pode ser uma oportunidade de discutir as possibilidades e reflexos da ação humana, em que se consideram aspectos sociais e geográficos, assim como ficcionais.
\end{abstract}

\section{Palavras-chave}

espaço; ensino; interdisciplinaridade; conhecimento.

\footnotetext{
* Universidade Regional do Noroeste do Estado do Rio Grande do Sul.

** Universidade Regional do Noroeste do Estado do Rio Grande do Sul.
} 


\section{Resumen}

La cuestión referente a la interdisciplinaridad es un tema recurrente en la educación de Brasil. Ese término está presente en los documentos oficiales que regulan la enseñanza, los Parámetros Curriculares Nacionales - PCNs y las Orientaciones Curriculares para la Enseñanza Media - OCEM. Teniendo en cuenta la importancia dada a la integración de las diferentes áreas del conocimiento en la escuela, se busca en este texto verificar las posibilidades de estudio del concepto de espacio, desde una perspectiva de interface para las áreas de la geografía, sociología y literatura. La literatura, aunque no se comprometa a ser un retrato fiel de la realidad, la representa a través de la verosimilitud, incluyendo en esto el medio (físico y social) en que el personaje adquiere sus motivaciones y vive la trama. Así, el escoger una obra literaria, teniendo en cuenta el tema que se pretende trabajar en el área de la sociología o geografía, puede ser una oportunidad de discutir las posibilidades y reflejos de la acción humana, en que se considera aspectos sociales y geográficos, así comoficticios.

\begin{abstract}
The discussion about interdisciplinary is a current theme in the Brazilian education. This word is presented in the official documents that rule teaching in the country. Considering the importance of integrated different knowledge areas at school, this text tries to verify the study possibilities of the concept of space through the relation among geography, sociology, and literature. For this, the concept of space is analyzed from Santos (1988; 2004; 2006), Bourdieu (2002) and Brandão (2014). From this, taking as an analyzing object the literary book Quem faz gemer a terra from Charles Kiefer, it will be discussed possibilities of an interdisciplinary work with concepts from three different areas. Therefore, it understands that this proposal allows the students a bigger comprehension of the concepts. Beyond it provides to the student to relate the concepts to his life and understand that the knowledge is not fragmented, but it makes relations.
\end{abstract}

\section{Palabras clave}

espacio; enseñanza; interdisciplinaridad; conocimiento.

\section{Keywords}

space; teaching; interdisciplinary, knowledge. 


\section{Introdução}

O ensino escolar brasileiro é organizado por um conjunto de normas legais que definem a estrutura do sistema de educação. Dentre essas, a mais abrangente é a Lei de Diretrizes e Bases de 1996 - LDB/96 (Lei no 9.394 de 20 dezembro de 1996), que define o sistema de educação, estipula as finalidades, objetivos, bem como os níveis e as modalidades do ensino, entre outras questões norteadoras. Destaca-se ainda na LDB/96, o esforço de educadores do país que realizaram um movimento em direção ao ensino desfragmentado e contextualizado, que levasse em conta inclusive os "conhecimentos e habilidades adquiridos pelos educandos por meios informais [...] auferidos e reconhecidos mediante exames". (LDB, 1996, p.27).

Adicionalmente, a legislação brasileira normatiza o ensino de maneira mais específica, cita-se aqui, os Parâmetros Curriculares Nacionais PCNs (Ministério da Educação [MEC], 2000) e Orientações para o Ensino Médio - OCEM (MEC, 2006). Essas normas direcionam o ensino para uma integração entre as áreas do saber sem, contudo, desconsiderar a importância de cada disciplina, isto é, a partir de uma concepção pedagógica interdisciplinar.

É importante enfatizar que a interdisciplinaridade supõe um eixo integrador que pode ser o objeto de conhecimento, um projeto de investigação, um plano de intervenção. Nesse sentido, ela deve partir da necessidade sentida pelas escolas, professores e alunos de explicar, compreender, intervir, mudar, prever, algo que desafia uma disciplina isolada e atrai a atenção de mais de um olhar, talvez vários. (PCNs, 2000, p.76).

Nessa perspectiva, a abordagem interdisciplinar, conforme expresso nos PCNs, "não elimina o ensino de conteúdos específicos, mas considera que os mesmos devem fazer parte de um processo global com várias dimensões articuladas". (MEC , 2000, p.18). Ainda nesse caminho, verifica-se também nas OCEM (MEC, 2006) um exemplo de trabalho interdisciplinar abrangendo as disciplinas de Língua Portuguesa, Artes, Geografia e História, que toma como base músicas, textos literários que tratam de um período histórico, no caso, o período da Ditadura Militar no Brasil.

Pode-se destacar as peculiaridades regionais, sociais, os movimentos populares nesse contexto, sem desconsiderar a abordagem do conteúdo disciplinar. Práticas como essa podem ser compreendidas "como uma tentativa de não fragmentar, o processo de formação do aluno, [...] as diferentes dimensões implicadas na produção de sentidos" (MEC , 2006, p.28), uma vez que elas permitem um trabalho que considera a contextualização permitindo o estabelecimento de uma interação entre conhecimentos disciplinares.

Assim, no presente texto nos baseamos na perspectiva de eixo integrador para debatermos teoricamente sobre a possibilidade de trabalhar com três disciplinas: Geografia, Literatura e Sociologia, tomando por base uma obra literária em uma perspectiva interdisciplinar. Levamos em conta a exposição de um conceito comum a todas, o conceito de espaço, a fim de que elas pudessem, além de contextualizadas, serem trabalhadas de maneira a exceder os limites de abrangência de cada disciplina.

Desse modo, optamos por tomar como ponto de conexão, ou como mencionado nos PCNs - "eixo integrador" - a obra Quem faz gemer a terra, de Charles Kiefer. A partir desse texto literário, realizaremos a apresentação do conceito de "espaço" nas três disciplinas estabelecendo posteriormente uma interlocução entre essas áreas do saber.

\section{A obra literária e o autor}

A obra Quem faz gemer a terra foi escrita pelo escritor gaúcho Charles Kiefer $^{1}$ em 1991 e foi inspirada em fatos reais que aconteceram e que dizem respeito a morte de um soldado que foi golpeado por uma foice durante um protesto dos Sem Terra ${ }^{2}$ (MST). A narrativa aborda temais sociais, e ainda que tenha elementos da realidade trata-se de um texto literário. A obra de Kiefer se assemelha muito com as ideias dos escritores da década $30^{3}$, no Brasil, em que através da literatura se denunciavam problemas sociais da realidade do país.

Narrada em primeira pessoa pela personagem Mateus, protagonista da história, a obra traz um relato que vai desde sua infância até a idade adulta. Da infância relata a convivência e o carinho que tinha por seu avô, a vida de menino que mora no campo. No entanto, essa simplicidade e tranquilidade são quebradas quando a família passa a enfrentar dificuldades financeiras após o endividamento para manter e cultivar a pequena propriedade. Como alternativa, Mateus e sua família passam a viver em um acampamento dos Sem Terra. Mateus casa-se, tem filhos e vive a lutar pela reforma agrária almejando conseguir um pedaço de terra para viver com a família. Nesse espaço de convívio, Mateus torna-se um líder no acampamento e participa de diversas manifestações nas quais, juntamente com as demais famílias que vivem no acampamento, luta pela reforma agrária. Todavia, durante um confronto com a polícia, em uma manifestação na cidade de Porto Alegre, Mateus com um golpe de foice atinge um soldado que acaba morrendo. Em consequência desse ato Mateus vai preso. Da prisão passa a narrar a sua própria história e

1 Charles Kiefer nasceu em Três de Maio, RS. É professor de literatura e oficinas literárias. Publicou mais de trinta títulos. Entre eles: O pêndulo do relógio; A dentadura postiça; Dedos de pianista; Quem faz gemer a terra, entre outros.

2 O Movimento dos Trabalhadores Rurais Sem Terra (MST), mais conhecido como Movimento dos Sem Terra, é um movimento social que luta, basicamente, pelo direito à terra, pela reforma agrária, bem como por mudanças na sociedade.

3 Podemos designar o romance de 30 como o "conjunto de narrativas, escrita entre os anos de 1930 e 1970, por uma mesma geração, oriunda de famílias oligárquicas rruinadas ou decadentes, com uma visão de mundo crítica, idêntico sentido missionário da literatura e padrões artísticos comuns, bastantes próximos do realismo do século XIX”. (Gonzaga, 2015, p.347). 
compreende o porquê de estar ali. Pois, através do relato a personagem se dá conta que a sua situação atual é fruto de uma questão social comum aos pequenos proprietários de terras da região sul do Brasil, que precisam de auxílio para cultivá-la, endividando-se e buscando no êxodo rural ou na reforma agrária uma saída para a sobrevivência.

\section{O espaço literário}

O espaço é abordado por diversas áreas do conhecimento assumindo assim diferentes conceitos, bem como a cada teoria, ainda que dentro de uma mesma área do saber. Neste item, daremos ênfase ao espaço tratado pela literatura que também possui diferentes enfoques. A questão espacial no campo literário, de acordo com Brandão (2013), possui quatro principais modos de abordagens sendo estes: "representação do espaço; espaço como forma de estruturação textual; espaço como focalização; espaço da linguagem." (p. 58).

A primeira abordagem diz respeito aquela que se interessa pela representação do espaço no texto literário. Sendo assim, o espaço é considerado como categoria que faz parte do universo extratextual e não há nenhuma indagação sobre ele. Nesse tipo de abordagem, são atribuídas ao espaço características físicas e passa a ser visto como cenário, lugares de pertencimento das personagens ou ainda como recurso de contextualização. E também como:

[...] significados tidos como translatos: o "espaço social" é tomado como sinônimo de conjuntura histórica, econômica, cultural e ideológica, noções compreendidas segundo balizas mais ou menos deterministas; já o "espaço psicológico" abarca as "atmosferas", ou seja, projeções, sobre o entorno, de sensações, expectativas, vontades, afetos de personagens e narradores, segundo linhagens variadas de abordagem da subjetividade, entre as quais são bastante comuns a psicanalítica e a existencialista. (Brandão, 2007, p. 208).

O segundo modo refere-se a procedimentos formais ou ainda de estruturação textual. Tende, pois, a considerar como espaço todos os recursos que produzem o efeito de simultaneidade e defende que é por meio dela que se atinge a totalidade da obra. Nessa abordagem, há um desdobramento lugar/espaço que reflete no próprio entendimento do que é a obra.

Por um lado, são partes autônomas, concretamente delimitadas, mas que podem estabelecer articulações entre si [...] por outro, é a interação entre todas as partes, aquilo que lhes concede unidade, a qual só pode se dar em um espaço total, absoluto e abstrato, que é o espaço da obra. (Brandão, 2007, p. 210).

O terceiro modo, a focalização, é responsável pelo ponto de vista, isto é, de que há na literatura um tipo de visão. Nessa perspectiva, o espaço pode ser entendido como espaço observado e também em espaço que torna possivel a observação. "Observar pode equivaler a mimetizar o registro de uma experiência perceptiva. Por essa via é que se afirma que o narrador é um espaço, ou que se narra sempre de algum lugar". (Brandão, 2007, p.211).

Por fim, o espaço da linguagem, entende-se que há uma espacialidade que é própria da linguagem. Nesse entendimento, a palavra também é um espaço uma vez que ela "é composta de signos que possuem materialidade. A palavra é uma manifestação sensível, cuja concretude se demonstra na capacidade de afetar os sentidos humanos, o que justifica que se fale da visualidade, da sonoridade, da dimensão do tátil do signo verbal." (Brandão, 2013, p. 64).

Não é nossa intenção nesse texto fazermos uma discussão mais aprofundada de cada uma dessas abordagens, apenas salientar que o espaço pode ser entendido por diferentes perspectivas na obra literária. Por outro lado, é importante destacar que o espaço contribui significativamente no texto literário sendo, pois, um elemento importante na narrativa. Embora tratado por muitos autores como simples acessório, o espaço literário está para além de descrição de cenários. Ele é importante no conjunto da narrativa, pois além de espaço físico também representa o espaço social e o espaço psicológico onde se desenvolve a narrativa e, portanto, pode ser explorado junto com os demais elementos da narrativa: tempo, personagem, narrador, foco narrativo.

\section{O espaço geográfico}

Neste item, abordamos o espaço geográfico. Para a geografia o espaço é entendido como espaço apropriado pelos homens, isto implica que seu estudo se dê não somente sobre objetos fixos ou móveis, mas também sobre os sujeitos e suas ações.

O espaço não é nem uma coisa, nem um sistema de coisas, senão uma realidade relacional: coisas e relações juntas. Eis por que sua definição não pode ser encontrada senão em relação a outras realidades: a natureza e a sociedade, mediatizadas pelo trabalho. (Santos, 1988, p. 10).

Baseadas nas ideias do geógrafo Milton Santos, consideramos o espaço geográfico como natural e social:

Não é o espaço, portando, como nas definições clássicas de geografia, o resultado de uma interação entre o homem e a natureza bruta, nem sequer um amálgama forma pela sociedade de hoje e o meio ambiente. 0 espaço deve ser considerado com um conjunto indissociável de que participam, de um lado, certo arranjo de objetos geográficos, objetos naturais e objetos sociais, e, de outro, a vida que os preenche e os anima, seja a sociedade em movimento. (Santos, 1988, p. 10) 
Como destacou Santos (1988), o espaço é uma realidade relacional. É por isso que não é possível defini-lo sem relacioná-lo com outras realidades, isto é, a natureza e a sociedade mediatizadas pelo trabalho. Desta forma, é impossível pensar o espaço sem a sociedade que o movimenta, que interage com ele. E a geografia como ciência social tem preocupação em estudar o espaço e suas relações.

Diante disso, entendemos não ser possível deixar de considerar também o mundo globalizado em que estamos inseridos, e em consequência disto a aproximação de espaços e de povos a que estamos sujeitos, ainda que seja por padrões econômicos. De acordo com Cavalcanti (2008), o espaço geográfico é concebido, intelectualmente, como um produto social e histórico que permite analisar a realidade em sua dimensão material e em sua representação. "O espaço é resultado da ação dos homens sobre o próprio espaço, intermediados pelos objetos naturais e artificiais". (Santos, 1988, p.25).

O espaço, sem dúvida, é testemunha e veículo dessa dinâmica. Nele são travados combates, estão cicatrizadas de lutas, erguem-se monumentos ao novo tempo e através de seus signos há a realização simbólica daquilo que comumente se concebe como "vida moderna". Em síntese, no espaço estão os signos da permanência e da mudança, e são vividos os ritos da ordem e do caos, da disciplinarização e dos desregramentos. Seus múltiplos sentidos são vivenciados, a cada instante, nos mais diferentes lugares do planeta. (Haesbaert, 2013, p. 81).

Desse modo, os espaços são construídos ao longo da construção da sociedade, Callai (2009). As relações sociais são materializadas em edificações que podem ser observadas fisicamente, e é, pois, nesta materialização que se torna possível interpretar a realidade. 0 olhar espacial supõe olhar a realidade social verificando as marcas inscritas nesse espaço.

O papel do espaço, hoje indissociável em suas perspectivas "natural" e "social", pode ser interpretado tanto como "rugosidade" ou constrangimentos, que redirecionam os processos sociais e econômicos, quanto como referenciais inseridos na vida cotidiana e que perpassam nossas identidades coletivas. (Haesbaert, 2013, p. 81).

Assim, a geografia trabalha com conhecimentos sobre o espaço na tentativa de desenvolver o raciocínio espacial, que se entende ser necessário ao exercício da cidadania, uma vez que é uma dimensão da realidade. Uma das formas de contribuir com o raciocínio espacial seria através de conceitos, os quais aconteceriam através de processos de construção de instrumentos simbólicos que ajudam na relação do sujeito com o mundo (Cavalcanti, 2008). O que se destaca aqui é o fato de que o estudo do espaço possibilita ao aluno conhecer melhor a sua realidade, ao mesmo tempo que interpretá-la.

\section{O espaço social}

Na área da sociologia é possível encontrar o conceito de espaço social em algumas obras do sociólogo francês Pierre Bourdieu, esse conceito representa uma ruptura com as concepções tradicionais de estudo dos grupos sociais. A tradição de estudos sociológicos, conforme Bonnewitz (2003), estrutura-se em duas correntes, uma baseada em Marx, cuja compreensão de divisão e estrutura da sociedade se dá a partir de caracteres econômicos e outra corrente, inspirada em Weber, em que a sociedade possuiria três critérios de classificação: o poder, o prestígio e a riqueza.

Contudo, para Bourdieu (2002) essas apreensões são redutoras da realidade, dessa maneira ele inaugura o que chama de topologia social:

Num primeiro tempo, a sociologia apresenta-se como uma topologia social. Pode-se assim representar o mundo social em forma de um espaço (com várias dimensões) construído na base de princípios de diferenciação ou de distribuição constituídos pelo conjunto das propriedades que atuam no universo social considerado, quer dizer, apropriadas a conferir, ao detentor delas, força ou poder neste universo. (pp. 133-134).

Sob essa perspectiva, os agentes sociais ocupam posições nesse espaço que são definidas, conforme Bourdieu (2002), pelo conjunto de propriedades que promovem a diferenciação. É importante destacar que esse espaço é virtual, não há uma separação explícita, mas se torna possível por meio das relações entre "cultura, classes, indivíduos, sistema educacional, baseado nas relações existentes entre os agentes sociais" (Pereira \& Catani, 2002) que estabelecem valores provocando um campo de interações entre as posições diversas do espaço social. É nesse ponto que ocorre o rompimento com a tradição dos estudos sociológicos, pois as propriedades responsáveis pela distinção social não são unicamente econômicas conforme Marx, ou as três classificações de Weber, isto é, poder, prestígio e riqueza.

A diferenciação social nesse contexto ocorre pela desigual distribuição dos capitais. Dessa maneira, se faz necessário analisar com atenção o sentido dado para o termo "capital" por Bourdieu, pois "a escolha dos meios linguísticos e dos gêneros de discurso é determinada, antes de tudo pelas tarefas (pela ideia) do sujeito do discurso (ou autor) centradas no objeto e no sentido". (Bakhtin, 2003, p. 289).

Além de que, o campo semântico expressa uma variedade de sentidos que o mesmo vocábulo pode ter. Assim, levando isso em consideração, percebe-se que a interpretação primeira a que o termo remente é de acordo com a definição encontrada nos dicionários, ou seja, capital é "patrimônio; riqueza capaz de produzir renda; [...] bens e valores usados na movimentação de negócios". (Houaiss e Villar 2009, p. 162). Nesse sentido, o termo capital ainda está bastante relacionado ao conceito marxista. 
No entanto, conforme afirmamos, nos estudos do sociólogo francês há uma ruptura com a escola de Marx. De modo que, para Bourdieu o capital que distingue e divide o espaço social abrange a área econômica, mas não se limita a ela. Além disso, pode ser essencialmente dividido em quatro, quais sejam:

O Capital Econômico, que é constituído pelos diferentes fatores de produção (terras, fábricas, trabalho) e pelo conjunto dos bens econômicos: renda, patrimônio, bens materiais; o Capital Cultural, que corresponde ao conjunto das qualificações intelectuais produzidas pelo sistema escolar ou transmitidas pela família [...]; o Capital Social, que se define essencialmente como o conjunto das relações sociais de que dispõe um indivíduo ou grupo. A detenção deste capital implica um trabalho de instauração e manutenção das relações, isto é, um trabalho de sociabilidade: convites recíprocos, lazer em comum, etc.; o Capital Simbólico, que corresponde ao conjunto dos rituais (como as boas maneiras ou o protocolo) ligados à honra e ao reconhecimento [...] as regras de boa conduta não são apenas exigência do controle social, mas são constitutivas de vantagens sociais com consequências efetivas. (Bonnewitz, 2003, pp. 53-54).

Este último capital mencionado, o capital simbólico, pode ser considerado também como reconhecimento, prestígio em um grupo social. Assim, percebe-se no conceito de espaço social de Bourdieu uma fusão entre as concepções marxistas e weberianas de sociedade.

Para aludir à ação dos capitais, Bourdieu (2002) relaciona o espaço social e espaço geográfico exemplificando a organização das cidades entre centro e periferias, sendo que, em regra, nas periferias das cidades os habitantes possuem um volume global dos capitais inferior aos moradores do centro da cidade. Esse é apenas um exemplo, mas representa a força invisível de diferenciação social promovida pelo acúmulo desigual de capitais.

\section{A obra literária e sua relação com os diferentes conceitos de espaços}

Considerando as definições de espaço abordadas, chamamos a atenção para as possibilidades de estudo que o texto literário permite. Neste texto, optamos por apresentar como o conceito de espaço é entendido a partir da literatura, da geografia e da sociologia na obra Quem faz gemer a terra de Charles Kiefer. A proposta de estudo pode ser trabalhada tanto no Ensino Fundamental (sétimo, oitavo e nono anos), como também no Ensino Médio ( $1^{\circ} .2^{\circ}$ e $3^{\circ}$ anos), dependendo da abordagem do professor. No entanto, no Ensino Médio, além da literatura e da geografia, o espaço social pode ser tratado pela disciplina de sociologia; já no Ensino Fundamental, por não ter no currículo brasileiro a disciplina de sociologia, o espaço social pode ser abordado tanto pela literatura que é trabalhada junto com a disciplina de língua portuguesa como pela geografia.
Para isso, em um primeiro momento, a fim de levar em conta o conhecimento prévio dos alunos, podem ser levantadas questões sobre o que entendem/conhecem por latifúndios, minifúndios, MST, reforma agrária, pequenos proprietários de terras, entre outras. Em seguida, apresentar a obra Quem faz gemer a terra de Charles Kiefer. Após a leitura, discutir em grupos, o enredo da obra solicitando que os alunos identifiquem semelhanças com os conceitos anteriormente levantados (latifúndios; minifúndios; MST, reforma agrária; pequenos proprietários, etc.). Em seguida, os alunos podem retornar à obra, a fim de perceberem como são expressos os conceitos de espaço das três áreas do saber.

Podemos verificar na obra em estudo, quando se identifica o espaço literário, a referência à casa de Mateus que pode ser representada pelo seguinte fragmento:

(...)da casa em que nasci nada sobrou, a não ser os quatro paus de guajuvira que serviam de alicerce. Era uma casa grande, de cumeeira alta e vastos janelões, forte e orgulhosa. Não se ria nem se espante, que as coisas também têm sentimento. O madeirame, as vigas, os barrotes, tudo naquela casa era de honesto proceder. (Kiefer, 2006, p. 13).

Nessa passagem, identificam-se características do espaço apresentada nos conceitos de espaço literário. Sobre as quais, chama-se atenção para o universo extratextual, quando faz referência ao sentimento, implícito, de Mateus com a casa, além da atribuição de características humanas para a casa - "orgulhosa" - identificando-a como um lugar de pertencimento do personagem. Dessa maneira, o espaço é visto como algo além de um simples cenário em que se desenrolam os acontecimentos.

O espaço geográfico é marcado no texto em vários momentos. Chamamos atenção para um fragmento em especial:

A tapera. O começo dos começos. Quando chovia, ficava tudo difícil de sair da canhada. o rio subia e água alcançava o galinheiro. Por isso, na hora de construir a casa nova, escolhemos o lugar mais alto e mais perto do estradão. Naquele tempo, o pai ainda tinha ainda dezoito hectares de terra e nada na cabeça. Vendeu dez para fazer a casa nova. hoje, com os mesmos dez, construía dez daquelas. (Kiefer, 2006, p. 19).

Aqui, percebe-se o espaço geográfico como espaço das relações entre os objetos naturais e o homem e, essas relações não são estáticas estão em constante movimento. A mediação do homem com o espaço conforme o excerto varia, tanto pela ação dos objetos naturais como pelas ações humanas.

No que diz respeito ao espaço social, no livro é possível citarmos um exemplo de relação conflituosa em função do espaço social e geográfico. Quando os integrantes do MST, agentes sociais com menor acúmulo de capitais cultural, econômico, buscam ocupar o espaço geográfico dos 
agentes sociais com maior acúmulo de capital, os fazendeiros ou policiais, ocorre o conflito social. Isso se dá em função, segundo a lógica do espaço social de Bourdieu, de que o espaço social é dividido pelas relações de poder existentes entre os diversos atores que constituem divisões teóricas ou virtuais que na vida real se refletem na divisão geográfica dos espaços. No texto de Kiefer (2006) destaca-se o seguinte excerto:

Na hora da raiva fiquei cego - e tinha mais calor, os tiros, o sangue, a gritaria, o ardume do gás nos olhos e na garganta. Você não esteve lá não sabe como foi. Eu the digo: uma guerra de verdade. Num lado, os colonos, com enxadas facões e foices; no outro, soldados, armados de fuzis e metralhadoras, bombas de gás e cassetetes. Disseram depois que os colonos queriam confusão, não é verdade. 0 que o movimento Sem-Terra queria era mostrar vontade de lutar pelo que era um direito nosso: a terra pra plantar e viver. (Kiefer, 2006, p. 67).

Desta forma, fica em evidência que os três espaços: literário, geográfico e social se inter-relacionam, uma vez que Kiefer (2006) a partir do espaço literário, que é o espaço onde se desenrola os fatos, do espaço geográfico marcado pela terra como território e lugar de pertencimento de Mateus, retrata um problema social enfrentado pelos pequenos agricultores marcando assim o espaço social. O que nos leva a identificar a possibilidade de trabalhar com a obra literária de maneira interdisciplinar a partir de conceitos de três áreas do saber.

\section{Considerações finais}

Neste texto, levando em conta que a interdisciplinaridade é apresentada nos documentos oficiais que normatizam a educação brasileira como uma possibilidade de promover a interação entre disciplinas, estabeleceu a proposta de trabalhar com três áreas do saber de maneira interdisciplinar, tomando como base a obra literária Quem faz gemer a terra de Charles Kiefer (2006).

Para desenvolver uma discussão teórica, apresentamos primeiramente um conceito comum na geografia, literatura e sociologia: o espaço, a fim de verificar a possibilidade de abordar esse conceito a partir da obra literária tomada como objeto de análise, no intuito de permitir ao aluno a compreensão contextualizada e não fragmentada dos conceitos.

Dessa maneira, apresentamos o espaço literário visto como algo além de um simples cenário em que se desenrolam os acontecimentos, isto é, um espaço extratextual de significações. 0 espaço geográfico como espaço das relações não estáticas entre os objetos naturais e o homem e, por fim, o espaço social marcado pelas relações de poder, existentes entre os diversos atores, orientadas pelo acúmulo de capitais. Destacamos ainda que os três espaços mencionados se relacionam na obra.

Assim, a partir da discussão proposta entendemos ser possível um estudo não fragmentado que permite ao aluno apreender os conceitos de cada disciplina de maneira que a aprendizagem seja significativa e que se interrelacione com o mundo da vida.

\section{Referências}

Bakhtin, M. (2003). Estética da criação verbal. Tradução do russo Paulo Bezerra. São Paulo: Martins Fontes.

Bonnewitz, P. (2003). Primeiras lições sobre a sociologia de P. Bourdieu. Tradução de Lucy Magalhães. Petrópolis, RJ: Vozes.

Bourdieu, P. (2002). O Poder Simbólico. 5a ed. Tradução Fernando Tomaz. Rio de Janeiro: Bertrand Brasil.

Brandão, L. (2013). Teorias do espaço literário. São Paulo: Perspectiva.

Brandão, L. (2007). Espaços Literários e suas expansões. Revista Aletria, 15, pp. 207-220.

Callai, C. (2009). Estudar o lugar para compreender o mundo. Em Castrogiovani, A. C. (org), Ensino de Geografia: práticas e textualizações no cotidiano. (7. ed.; Cap. 2.; pp. 83- 134). Porto Alegre: Mediação. 
Cavalcanti, L. (2008). A geografia escolar e a cidade: Ensaio sobre o ensino de geografia para a vida urbana cotidiana. Campinas: Papirus.

Gonzaga, S. (2015). Curso de literatura brasileira. (6 ed.). Porto Alegre: Leitura XXI.

Haesbaert, R. (2013). Territórios Alternativos. Niterói: EdUFF; São Paulo: Contexto.

Houaiss, A. \& Villar, M. de S. (2011). Dicionário Houaiss da Língua Portuguesa. Rio de Janeiro: Moderna.

Kiefer, C. (2006). Quem faz gemer a terra. (7.ed.). Rio de Janeiro: Record.

Lei № 9.394 de 20 de dezembro de 1996 (1996). Estabelece as diretrizes e bases da educação nacional. Diário Oficial da União. Brasília, DF. Disponível em: http://portal.mec.gov.br/seesp/arquivos/pdf/lei9394_Idbn1.pdf. Acesso em: 10 de junho de 2016.

Ministério da Educação [MEC]. (2000). Parâmetros Curriculares Nacionais: Ensino Médio. Secretaria de Educação Média e Tecnológica. Brasília: Autor.

Ministério da Educação [MEC]. (2006). Orientações curriculares para o ensino médio; linguagens, códigos e suas tecnologias. Brasília: Autor, Secretaria de Educação Básica.

Pereira. G. R. de M.; Catani, A. M. (2002). Espaço social e espaço simbólico: introdução a uma topologia social.Revista Perspectiva .20, 107-120. Disponível em: https://periodicos.ufsc.br/index.php/perspectiva/article/view/10279.

Santos, M. (1988). Metamorfoses do espaço habitado, fundamentos Teórico e metodológico da geografia. São Paulo: Hucitec. 